\title{
Liberalismo e divergência: a representação das subjetividades animais na Inglaterra vitoriana
}

\section{Liberalism and divergence: representations of animal subjectivities in Victorian England}

\author{
Luciana Murari ${ }^{i}$ \\ ' Escola de Humanidades/Pontifícia Universidade Católica do Rio Grande do Sul. \\ Porto Alegre - RS - Brasil \\ orcid.org/0000-0003-1517-1016 \\ luciana.murari@pucrs.br
}

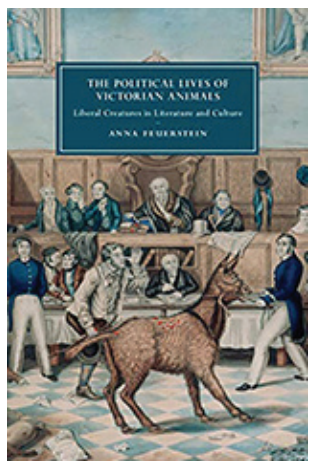

FEUERSTEIN, Anna. The political lives of Victorian animals: liberal creatures in literature and culture. Cambridge: Cambridge University Press, 2019. 270 p.

No cenário tecnológico e ambiental contemporâneo, sob a égide do conceito de Antropoceno, ascende a demanda pela problematização dos sentidos de "humanidade" e "humanismo". Nessa perspectiva, a produção de conhecimento orienta-se para a exploração de objetos e abordagens que transcendem as sociedades humanas e as reposicionam em relação a outros sujeitos igualmente dotados de interioridade e agência.

Abraçando a pesquisa historiográfica e a crítica político-cultural, o trabalho de Anna Feuerstein, professora da Universidade do Havaí em Manoa, inscreve-se nesse contexto. The political lives of Victorian animals divide-se em duas vertentes principais: a incorporação dos animais na comunidade política liberal forjada ao longo do século XIX inglês e a representação da subjetividade animal pela produção intelectual da época.

A autora beneficia-se dos estudos vitorianos que abordam o liberalismo como uma filosofia política que endossa preceitos regulatórios conformadores das práticas e crenças da vida cotidiana. No primeiro capítulo do livro, Feuerstein (2019) demonstra como a politização e liberalização dos animais operou-se a partir da mobilização de seus defensores em prol de uma legislação específica, ponto de inflexão para seu ingresso na esfera política. As ações nesse sentido incorporam em primeiro lugar animais de trabalho, décadas depois defendem os animais domésticos e apenas no fim do período preocupam-se com os animais selvagens em cativeiro. Mesmo aqueles não inscritos na ordem liberal - como as feras nativas de outras regiões do Império eram regulados pela racionalidade governamental, inclusive por processos de extermínio.

Ao longo do século XIX, o discurso dos defensores dos animais os converte em sujeitos dotados de pensamento, consciência e afetividade. Assimilados aos indivíduos liberais, foram legitimados como parte da comunidade política, desde que obedientes à superioridade 
hierárquica dos homens e concordantes com a domesticação. Dotados de representação política, os animais foram incorporados ao sistema vigente de controle das condutas.

Fazendo uso do conceito sorvido de Michel Foucault, no segundo capítulo da obra a autora demonstra o exercício do "poder pastoral", conjunto de estratégias para guiar o comportamento por intermédio da disseminação de ideologias que condicionam as vontades e conduzem a construção de si. As estruturas de poder submetem os animais ao conhecimento e à governabilidade liberais, de maneira que a empatia e a prática do cuidado convergem com os expedientes do biopoder exercidos por meio de sua exploração e sujeição, mesmo em formas aparentemente benignas.

Os capítulos seguintes tematizam a literatura como linguagem privilegiada para a conversão dos animais em individualidades subjetivadas. O romance abriu espaço, aponta Feuerstein, para a expressão de sua interioridade em comunidades mais amplas que a esfera da política. Pela representação antropomórfica, valorizada como procedimento contrário ao antropocentrismo, os animais ganham voz no espaço público para apresentar suas demandas de inclusão, ao lado dos operários, das mulheres e dos sujeitos colonizados. Em diálogo com a recente crítica cultural do período e com a história dos animais, a autora observa como, na comunidade política vitoriana, o discurso os incorporou no contexto da "cognição liberal", que abarcava valores - como a objetividade, a convicção e a impessoalidade - e técnicas - como o livre pensamento, o raciocínio lógico e o debate interiorizado.

Em oposição ao status objetificado imposto aos animais, o livro evidencia como frequentemente eles são implantados na narrativa ficcional como personagens que combatem a submissão, afrontando a hierarquia que os rebaixava. A análise das obras de Charles Dickens e Lewis Carroll evidencia a habilidade desses escritores de, respectivamente, desarticular a submissão dos animais (e, simultaneamente, da classe operária) pelo aparato liberal, e perturbar as estratégias de domínio vigentes no sistema educacional.

A terceira parte do livro volta-se para a faceta biopolítica da conversão dos animais em capital, retomando os temas anteriores para refletir sobre os códigos da criação dos animais para consumo. A obra de Thomas Hardy, analisada no quinto capítulo, expressa a valorização dos animais e a defesa de seu tratamento justo e equânime, por meio do reconhecimento da multiplicidade das espécies que interativamente compõem a vida social. No último capítulo, a autora desloca o olhar para o contexto (anti-)colonial, demonstrando como, nos escritos de Olive Schreiner, a representação dos animais sul-africanos produziu concepções críticas da animalidade dentro do Império britânico, indicando dinâmicas relacionais alternativas ao modelo político vigente.

Em sua leitura crítica de obras canônicas da literatura inglesa, Feuerstein identifica a correspondência entre a separação de animais e humanos e a demanda de mantê-los disponíveis para a exploração social, o que se aplica não somente àqueles que possuem utilidade econômica, mas também àqueles com os quais são estabelecidas relações domésticas e de proteção. A referência, nesse caso, é a obra de Jacques Derrida ( $O$ animal que logo sou), para quem o mero pressuposto da animalidade não define a diversidade das espécies, produzindo o desconhecimento e a violência em direção aos não humanos, tidos como uma "alteridade absoluta". Na leitura da autora, os animais não são expressões apenas da diferença, mas de uma incognoscibilidade (unknowability). No livro, são enfatizados os 
momentos em que os vitorianos parecem conscientes de sua incapacidade de elaborar a subjetividade animal, de modo que a alteridade se torna uma alternativa à opressão exercida pelo pensamento liberal, que funciona em uma lógica especeísta (speciesist).

A autora encerra o livro advogando por uma democracia radical capaz de abrigar diversas categorias de sujeitos políticos, inclusive os animais em sua diversidade. Para tanto, seria necessário ultrapassar os modos por meio dos quais eles foram enquadrados na ordem liberal. Ao expor os discursos, práticas e representações que caracterizam as relações entre homens e animais, Feuerstein permite-nos vislumbrar o processo de enquadramento das espécies não humanas e os limites de sua incorporação como sujeitos políticos. A evidente incoerência entre as leis em defesa de seu cuidado e proteção e a continuidade de sua exploração demonstra que uma nova conceptualização dos limites entre os animais e os humanos torna-se obrigatória na ampliação da representação democrática para a totalidade dos seres participantes da vida social.

\section{REFERÊNCIAS}

FEUERSTEIN, Anna. The political lives of Victorian animals: liberal creatures in literature and culture. Cambridge: Cambridge University Press, 2019. 